\title{
TODO, PARA TODOS Y GRATIS: COORDENADAS PARA GARANTIZAR LA INVIABILIDAD DE UN SISTEMA DE SALUD
}

All for all and for free: coordinates to turn impracticable a health system

${ }^{1}$ Universidad de Buenos Aires. Buenos Aires, Argentina.

Correspondência: Elian Pregno. E-mail: epregno@derecho.uba.ar.

Recebido em: 01/12/2016. Revisado em: 14/03/2016. Aprovado em: 20/03/2016. 


\section{RESUMEN}

El presente trabajo pretende anotar el fallo de la Corte Suprema de Justicia de la Nación Argentina recaído en autos caratulados: "Asociación Civil para la Defensa en el Ámbito Federal e Internacional de Derechos c/ Instituto Nacional de Servicios Sociales para Jubilados y Pensionados s/ amparo", en febrero de 2015. En primer término, se ofrece -en apretada síntesis- una referencia al caso, esclareciendo: las partes en litigio; la pretensión de la parte actora; el medio procesal interpuesto y la secuencia seguida en las sucesivas instancias, como así también los argumentos esgrimidos en cada una de ellas. A este último respecto, cabe destacar que el máximo tribunal argentino ha sentado como doctrina que resultan procedentes las acciones de clase interpuestas con el objeto de que el Instituto Nacional de Servicios Sociales para Jubilados y Pensionados brinde cobertura integral de prestaciones a personas con discapacidad, beneficiarias de pensiones no contributivas. En segundo lugar, se presenta la integración del sistema de salud en la Argentina y una serie de conjeturas en orden a la tensa relación que exhiben la justicia y la utilidad a la hora de fundamentar los derechos humanos -en general- y el derecho a la atención de la salud -en particular-.

\section{Palabras claves}

Acciones de Clase; Justicia; Sistema Único de Salud; Utilidad.

\section{ABSTRACT}

This paper aims to analyze a decision by the Argentinian Supreme Court of Justice involving the civil organizations DE.FE.IN.DER. (Defensa en el Ámbito Federal e Internacional de Derechos - National and international defence of rights) and "Pequeña Obra de la Divina Providencia" versus the Argentinian National Institute of Social Services for Pensioners. First, a reference to the case -a tight synthesis- is made, clarifying: the litigants; the claim; the interposed procedural in successive instances, as well as the arguments by each one. It is noteworthy that the maximum Argentinian court has accepted the class-actions as a way to force the Argentinian National Institute of Social Services for Pensioners to provide the complete package of benefits to persons with disabilities, beneficiaries of non-contributory pensions. Second, it is presented the integration of the health system in Argentina and a number of assumptions related to the tense relationship between the justice and the utility for justifying the human rights, in general, and the right to health, in particular.

\section{Keywords}

Class Actions; Justice; Unified Health System; Utility. 


\section{El caso}

Las asociaciones civiles “DE.FE.IN.DER.” (Defensa en el Ámbito Federal e Internacional de Derechos) y "Pequeña Obra de la Divina Providencia”, entrablaron una acción de amparo contra el Instituto Nacional de Servicios Sociales para Jubilados y Pensionados (INSSJP) a fin de garantizar a los beneficiarios de pensiones no contributivas el derecho a la cobertura integral de las prestaciones que las leyes $22.431 \mathrm{y}$ 24.901 establecen para las personas que viven con discapacidad.

De modo que:

1. Las partes del proceso son dos personas de existencia ideal:

(a) por la parte actora, concurren dos organizaciones no gubernamentales pretendiendo ejercer legitimación activa para tutelar derechos de incidencia colectiva; $y$,

(b) la requerida -popularmente conocida como "PAMI" en alusión al eslogan fundacional que refería al "Programa de Atención Médica Integral”-, también es una persona jurídica, aunque "de derecho público no estatal, con individualidad financiera y administrativa” (artículo $1^{\circ}$ de la Ley $19.032^{1}$ ).

2. Las amparistas pretenden que todas las personas con discapacidad, que resulten ser beneficiarias de pensiones no contributivas y, a la misma vez, se encuentren afiliadas al INSSJP, gocen del derecho a la cobertura integral de las prestaciones que prevé:

(a) la Ley 22.431, que crea el "Sistema de protección integral de los discapacitados"2; y,

(b) la Ley 24.901, que estableció el "Sistema de Prestaciones Basicas en Habilitacion y Rehabilitacion Integral a favor de las Personas con Discapacidad"3. Conforme al plexo normativo integrado por la Ley 18.910 y el Decreto No 432/1997 (con más sus respectivas disposiciones complementarias y modificatorias ${ }^{4}$ ), todas aquellas personas que

${ }^{1}$ Es importante destacar que la norma se sancionó en 1971, durante el gobierno dictatorial que interrumpió el orden institucional en 1966 derrocando al presidente constitucional Arturo Illia con la autodenominada "Revolución Argentina" (1966-1973), a instancias del por entonces presidente de facto Alejandro Lanusse, el último de los militares que se desempeñó al frente del Poder Ejecutvio Nacional antes de restablecer la continuidad democrática.

${ }^{2}$ Tal como quedara reflejado en la nota que antecede, esta norma se sancionó en 1981, durante el gobierno dictatorial que interrumpió el orden institucional en 1976 derrocando a la vicepresidenta constitucional María Estela Martínez de Perón, popularmente conocida como "Isabelita" y que ejercía la presidencia luego de la muerte Juan Domingo Perdón, su compañero de fórmula y de vida. El "Perído de Reorganización Nacional" se inició el 24 de marzo de 1976 y fue la última vez que los militares interrumpieron la continuidad democrática; de ahí, entonces, que la ley lleve la firma del dictador Jorge Rafael Videla.

3Sancionada: 05/11/1997; promulgada de hecho: 02/12/1997.

${ }^{4}$ La Ley N 18.910 (sancionada: 31/12/1970; publicada: 51/01/1971) introdujo una reforma en el "Régimen de Pensiones a la Vejez y por Invalidez", establecido por la Ley $N^{\circ} 13.478$ (sancionada: 29/09/1948; publicada: 21/10/1948) y su modificatoria Ley N 15.705 (sancionada: 20/09/1960 y publicada: 14/11/1960), facultando en el artículo $9^{\circ}$ al Poder Ejecutivo a otorgar pensiones inembargables a toda persona mayor de 60 años 0 imposibilitada de trabajar, sin recursos propios suficientes y que no capite en ningún sistema de previsión. Hay que decir que tanto la iniciativa como su primera modificación son tributarias de gobiernos democráticamente electos (el primero de Juan Domingo Perón y el de Arturo Forndizzi, respectivamente), mas la enmienda posterior la incorporó la llamada "Revolución Argentina" (ver nota 2). No puede soslayarse cómo gobiernos dictatoriales han asumido contradictorias posiciones tuitivas ante grupos vulnerables como ancianos y discapacitados. Luego, por expreso mandato legal, cupo reglamentar la potestad conferida; así, hoy en día, las pensiones son regidas por el Decreto N 432/1997 (del 15/05/1997), dictado durante el gobierno neoliberal encabezado por el Dr. Carlos Saúl Menem. 
acrediten una discapacidad que supere el $76 \%$ y, además, se encuentren en un estado de vulnerabilidad social, tienen derecho a ricibir una pensión no contributiva. Además, entre los beneficios, se encuentra contemplado el acceso al mínimo decente que el país ofrece desde el Programa Médico Obligatorio (PMO) para la la atención de la salud. Ahora bien, hay que decir que el fallo se expide sólo sobre la admisibilidadad de la acción y la consecuente apertura de la instancia extraordinaria.

3. El medio procesal interpuesto es la acción de amparo, que inaugura un porceso de naturaleza constitucional que alcanzó reconocimineto normativo en la cima del ordenamiento jurídico argentino a partir de la reforma a la Carta Magna en $1994^{5}$. El juez que previno fue el titular del Juzgado Federal Civil y Comercial $\mathrm{N}^{\circ} 11$, con asiento en la Capital Federal, y rechazó in limine la acción por entender que los actores careccían de legitimación activa. La decisión fue confirmada por la Sala I de la cámara del fuero, con arreglo a los siguientes justificativos:

(a) la acción de clase incoada pretende reducir la demora en el pago de las prestaciones a las prestatarias de salud. Esa pretensión, a criterio del tribunal de alzada, tenía naturaleza individual y exclusiva respecto de cada una de las empresas o profesionales que prestan sus servicios en el sistema de salud. De allí, entonces, que concluyese que las asociaciones actoras no podían reclamar el cumplimiento de los derechos emergentes de los contratos que firmaban los prestatarios con el INSSJP, ni sustituir a éstos en la acción por los daños que pudieran producirse en la relación contractual;

(b) de igual modo, agregó que las demoras indicadas en las prestaciones de los propios afiliados constituían un daño individual y propio de cada uno de los presuntos afectados y, por ende, exclusivo de cada afiliado del INSSJP. En esa inteligencia, sostuvo que cada uno de los afiliados tenía en este caso un derecho subjetivo, individual y exclusivo, que los legitimaba individualmente para reclamar el cese de la demora en la atención.

4. Contra esta decisión, la asociación civil DE.FE.IN.DER. interpuso ante la cámara un recurso extraordinario federal para llegar a la Corte Suprema de Justicia de la Nación

\footnotetext{
${ }^{5} \mathrm{Al}$ respecto, dice el artículo 43 de la Constitución Nacional Argentina: “Toda persona puede interponer acción expedita y rápida de amparo, siempre que no exista otro medio judicial más idóneo, contra todo acto $u$ omisión de autoridades públicas o de particulares, que en forma actual o inminente lesione, restrinja, altere o amenace, con arbitrariedad o ilegalidad manifiesta, derechos y garantías reconocidos por esta Constitución, un tratado o una ley. En el caso, el juez podrá declarar la inconstitucionalidad de la norma en que se funde el acto u omisión lesiva. Podrán interponer esta acción contra cualquier forma de discriminación y en lo relativo a los derechos que protegen al ambiente, a la competencia, al usuario y al consumidor, así como a los derechos de incidencia colectiva en general, el afectado, el defensor del pueblo y las asociaciones que propendan a esos fines, registradas conforme a la ley, la que determinará los requisitos y formas de su organización. Toda persona podrá interponer esta acción para tomar conocimiento de los datos a ella referidos y de su finalidad, que consten en registros o bancos de datos públicos, o los privados destinados a proveer informes, y en caso de falsedad o discriminación, para exigir la supresión, rectificación, confidencialidad o actualización de aquéllos. No podrá afectarse el secreto de las fuentes de información periodística. Cuando el derecho lesionado, restringido, alterado o amenazado fuera la libertad física, o en caso de agravamiento ilegítimo en la forma o condiciones de detención, o en el de desaparición forzada de personas, la acción de hábeas corpus podrá ser interpuesta por el afectado o por cualquiera en su favor y el juez resolverá de inmediato, aun durante la vigencia del estado de sitio".
} 
(CSJN), cuyo rechazo motivó que la accionante llegase en queja al máximo tribunal, argumentando que en el caso se encontraban comprometidos derechos de incidencia colectiva relacionados con la salud pública y que su impulso obedecía a la necesidad de garantizar una adecuada prestación de los servicios sanitarios, más allá de quiénes se beneficien con la acción, qué patología les afecte, cuáles sean las prestaciones individuales requeridas por cada uno. En suma, se procura que todas las personas con discapacidad gocen del derecho a la cobertura integral de las prestaciones dispuestas en las Leyes 22.431 y 24.901, en cumplimiento de la normativa emergente del bloque de constitucionalidad federal.

5. Finalmente, la CSJN -en coincidencia con el dictamen del Procurador General de la Nación- resuelve a favor de la actora y le reconoce legitimación activa. Para así resolver, los ministros del Alto Tribunal argentino Elena Highton de Nolasco, Carlos S. Fayt y Juan Carlos Maqueda, argumentaron que:

(a) el recurso extraordinario debía admitirse, toda vez que la sentencia de la Cámara clausuró la interpretación del artículo 43 de la Constitución Nacional de manera contraria a las pretensiones de la amparista en orden a su legitimación activa para reclamar la tutela judicial de derechos colectivos. En tal sentido, la CSJN se ocupa de enmarcar el caso en la doctirna que el propio tribunal sentó sobre derechos colectivos in re: "Halabi, Ernesto c/ PEN - Ley 25.873 y Decreto 1563/04 s/ amparo"6, para ello afirma que: el amparo promovido se refiere a intereses individuales homogéneos afectados por el obrar del INSSJP, en la medida que que es el citado organismo el que obstaculiza el acceso igualitario a prestaciones integrales de salud de una pluralidad indeterminada de niños, jóvenes y adultos con discapacidad, titulares de pensiones no contributivas;

(b) los derechos colectivos están reconocidos en el segundo párrafo del artículo 43 de la Constitución Nacional y las asociaciones civiles tienen legitimación activa para incoar acciones que los salvaguarden. Por eso, la CSJN es categórica: "la ausencia de una norma que regule en forma precisa y acabada el efectivo ejercicio de las acciones colectivas no puede dejar sin protección a derechos fundamentales consagrados en el texto constitucional";

(c) la admisión de las acciones colectivas requiere que los magistrados verifiquen:

- una causa fáctica común;

- una pretensión procesal enfocada en el aspecto colectivo de los efectos del hecho;

- que el interés individual considerado aisladamente no justifique la promoción de una demanda; $y$,

- que, pese a tratarse de derechos individuales, exista un fuerte interés estatal en su protección, sea por su trascendencia social o en virtud de las particulares características de los sectores afectados;

${ }^{6}$ Sobre el particular, conviene ver: Disponible en: <http://www.cij.gov.ar/nota-615-La-Corte-reconoce-accioncolectiva-y-da-alcance-general-a-un-fallo.html> Aceso en: 25 fev. 2009. 
- en el sub lite se reúnen los extremos precedemente referidos; a saber:

- la interposición del amparo persigue la protección de derechos individuales de una pluralidad relevante de sujetos;

- existe una conducta única y continuada que lesiona a ese colectivo y la pretensión se encuentra enfocada a los efectos comunes del problema, vinculado directamente con el derecho a la atención de la salud. Vale decir: se constata una homogeneidad fáctica y normativa, que hace razonable la promoción de una acción de amparo en defensa de los intereses de todos los afectados y justifica el dictado de un pronunciamiento único con efectos expansivos a todo el colectivo involucrado;

- aun cuando pudiera sostenerse que la consideración aislada del interés individual justifica la promoción de demandas individuales, no es posible soslayar el incuestionable contenido social del derecho involucrado, máxime cuando atañe a grupos que por mandato constitucional deben ser objeto de preferente tutela por su condición de vulnerabilidad: los niños, las mujeres, los ancianos y las personas con discapacidad?

La protección de los derechos que invocan hacen a la satisfacción de necesidades básicas y elementales a cargo del Estado. Estos aspectos cobran preeminencia por sobre los intereses individuales de cada afectado, al tiempo que ponen en evidencia, por su trascendencia social y las particulares características del sector involucrado, la presencia de un fuerte interés estatal para su protección, entendido como el de la sociedad en su conjunto".

\section{Anotaciones marginales}

Si bien el fallo de la CSJN: "Asociación Civil para la Defensa en el Ámbito Federal e Internacional de Derechos c/ Instituto Nacional de Servicios Sociales para Jubilados y Pensionados s/ amparo", que sintéticiamente hemos presentado en el apartado que antecede, se ocupa en gran medida de resolver la legitimidad de la actora para interponer la acción, creemos oportuno reparar en el carácter estelar que cabe asignar a la economía en su confronte permanente con los derechos humanos (en general), y con el derecho humano a la atención de la salud (en particular).

\footnotetext{
${ }^{7} \mathrm{Al}$ respecto, dice el artículo 75, inciso 23, de la Constitución Nacional Argentina: “Corresponde al Congreso: ... 23) Legislar y promover medidas de acción positiva que garanticen la igualdad real de oportunidades y de trato, y el pleno goce y ejercicio de los derechos reconocidos por esta Constitución y por los tratados internacionales vigentes sobre derechos humanos, en particular respecto de los niños, las mujeres, los ancianos y las personas con discapacidad. Dictar un régimen de seguridad social especial e integral en protección del niño en situación de desamparo, desde el embarazo hasta la finalización del período de enseñanza elemental, y de la madre durante el embarazo y el tiempo de lactancia".
} 
En atención a ello, a no dudarlo que en la atención de la salud se exaltan los desafíos que la utilidad le plantea a la justicia. Desde luego, es tan incómodo preguntarse cuánto cuestan los derechos como imprescindible formularse tal interrogante, sobre todo porque no es cierto que la atención de la salud sea gratuita. En otras palabras: que las personas no paguen para atender su salud, no significa que no haya costos. Desde luego, cuando se trata de grupos vulnerables (como los adultos mayores o las personas con discapacidad), los niveles de incomodidad para formular el planteo alcanzan niveles superlativos.

Ahora bien, sin ahondar más de la cuenta, hemos dicho ya

que no es sostenible en el tiempo un sistema de salud que observe simultáneamente las siguientes tres premisas: a) todas las prácticas-procedimientos-actos-intervenciones, sean diagnósticas, terapéuticas y/o preventivas, que el imperativo tecnológico habilita para atender la salud de la población; b) para todas las personas; $y, c)$ en condiciones de gratuidad. Mantener conjuntamente las tres coordenadas es a riesgo de la existencia misma del sistema; estamos tan convencidos de ello, como que resulta políticamente incorrecto decirlo ${ }^{8}$.

No es simpático decir que "todo, para todos y gratis" torna inviable la ecuación, pero no hay modelo que resista y lo peor que podemos hacer es negar la finitud de los recursos. Por obvio que sea, no es ocioso explicitar que los recursos son escasos, per definitionem, y las necesidades son múltiples, lo cual nos obliga a elegir.

A todo esto, se suma que si hay algo que guarda un verdadero comportamiento antistémico en la Argentina, entre otras cosas, es el sistema de salud. En efecto, lo informan tres sub-sistemas:

(a) el sub-sistema privado: que hace las veces de continente de las relaciones jurídicas guarecidas en la autonomía de la voluntad y las formas modernas de contratación. Vale decir: atiende la totalidad de los vínculos que los particulares y las empresas celebran entre sí en orden a la atención de la salud, sea mediante pagos directos en ocasión de la atención específica demandada o abonos prepagos;

(b) el sub-sistema de la seguridad social: que nuclea a las obras sociales, agentes que se financian con aportes de los trabajadores y contribuciones de la patronal. También se encuentran comprendidos los jubilados y pensionados y los trabajadores del sector público (universidades, poderes constituidos del estado, fuerzas 
armadas y de seguridad), tanto nacional como de cada una de las veinticuatro jurisdicciones locales. Así las cosas, los beneficiarios del INSSJP capitan en el sub-sistema de la seguridad social.

(c) el sub-sistema público: operado por el estado (nacional, provincial, municipal) para atender la salud de quienes no cotizan en ninguno de los dos sub-sistemas anteriores.

La Argentina, más temprano que tarde, deberá algún día encaminarse hacia un sistema único de salud, conforme a diseños similares a los ensayados en la región (Chile, Uruguay, Brasil). Ciertamente, la estructura federal del país obliga a considerar a la competencia para regular la materia sanitaria como exclusiva de las provincias hasta tanto no sean ellas mismas quienes expresamente la deleguen en la autoridad central ${ }^{9}$.

En ese escenario, no se trata de arancelar la salud sin más, ni de restringir in totum la cobertura, ni de hacer acepción de personas en orden al acceso a la atención de la salud. No. Se trata, pues, de extremar los recaudos de la democracia deliberativa ${ }^{10}$ para decidir, de la manera más participativa posible, de manera argumentada y con un irrenunciable sentido humanista: qué contingencias asumirá a su costo la sociedad, cuál será la intensidad de esas coberturas y quiénes están en mejores condiciones de asumirlas.

La inadecuación numérica de los bienes existentes y disponibles para satisfacer demandas en materia sanitaria se impone a poco de andar y reparar, por ejemplo, en que no hay tantas camas en los hospitales como individuos habitan las ciudades donde el nosocomio está emplazado.

Lo que intentamos reflejar es que no se puede pretender intervenciones exitosas en salud sin una dosis mínima de utilitarismo. Debemos decir sin miramientos que no se puede atender la salud sin una jerarquización atinada de un criterio de utilidad, principalmente para orientar el juicio de adjudicación de los recursos.

Puede ser que inicialmente la idea cause aversión, mas nadie que comprenda el funcionamiento de una sala de triage puede desconocer la premisa de que se atiende al que mejores chances tiene. Priorizar la atención o no del paciente, sopesando necesidades y recursos, en miras a sus posibilidades de

\footnotetext{
${ }^{9} \mathrm{Al}$ respecto, dice el artículo 121 de la Constitución Nacional Argentina: “Las provincias conservan todo el poder no delegado por esta Constitución al Gobierno federal, y el que expresamente se hayan reservado por pactos especiales al tiempo de su incorporación".

${ }^{10}$ ALEGRE, Marcelo; GARGARELLA, Roberto; ROSENKRANTZ, Carlos (Coords.). Homenaje a Carlos S. Nino. Buenos Aires: La Ley, 2008; ARANGO, Rodolfo. Filosofía de la democracia. Bogotá: Siglo del Hombre, 2007; GARGARELLA, Roberto. La justicia frente al gobierno. Barcelona: Ariel, 1996; SANTIAGO JUÁREZ, Rodrigo. Participación y deliberación como correctores del sistema democrático. Estudios Fronterizos, v. 10, n. 20, p. 129-152, 2009; entre otros.
} 
sobrevida, informa el juicio de relevancia que a diario llevan a la práctica emergentólogos y urgentólogos ${ }^{11}$.

En cierta medida y no sin sobresaltos, tomamos distancia de posiciones ético-normativas de corte deontológico, en tanto resultan relevantes para merituar el obrar profesional, pero no para pensar el funcionamiento del sistema de salud.

Y este es el punto neural de estas notas, cuya presentación puede desagregarse del siguiente modo:

(a) los derechos humanos descansan en un paradigma de fuerte apoyatura deontológica;

(b) el derecho a la atención de la salud, es un derecho humano;

(c) no se puede trabajar en salud sin una considerable dosis de utilitarismo;

(d) luego, ¿cómo se realiza el derecho humano a la atención de la salud?

El problema es enorme (literalmente: desborda a las normas) y, de algún modo, con este menudo problema debe enfrentarse a diario el juez cuando se le someten cuestiones relativas a la atención de la salud. Los operadores jurídicos le despliegan una batería de argumentos de corte deontológico mas no alcanzan realización sino en mediaciones utilitaristas.

El planteo es crucial y, según nos parece, reclama ser verbalizado con urgencia y atendido de manera interdisciplinaria, sobre todo porque las más de las veces los principios se forjan sin "olor a hospital en la nariz"; o sea: el Derecho ata pesadas cargas sobre los hombros del equipo de salud, desconociendo ese área del conocimiento.

\section{Intuición final}

Por obvio que resulte, no es ocioso decir que el derecho a la atención de la salud no es absoluto y reconoce límites. Así como nadie puede costear su propia salud, ningún estado puede destinar la totalidad del producto bruto para atender el sistema de salud. Los teóricos y los operadores jurídicos deben asumir que la satisfacción de los derechos sociales tiene lugar en un horizonte de comprensión atravesado por la escasez y que urge incorporar criterios de eficiencia y eficacia, pues de otro modo el derecho se torna insuficiente para recibir, contener, gestionar y satisfacer la demandas sanitarias.

\footnotetext{
${ }^{11}$ Salvando debidamente las distancias y sin ánimo de introducir imágenes que acaben por trivializar le complejidad de la cuestión tratada, los parámetros del triage se recrean cada vez que un avión se dispone a despegar. La puesta en escena de la tripulación ante el pasaje, mientras se reproduce el mensaje de seguridad, postula que: si un adulto viaja con un niño en brazos, ante una eventual despresurización de la aeronave, la mascarilla de oxígeno que se descuelga debe colocársela primero él y luego debe hacer lo propio con el pequeño. Confieso que la primera vez que escuché la advertencia me resultó inadmisibile. No podía pensar en anteponer mi bienestar al de mis hijos. Después, comprendí: si ante una situación de extremada gravedad no me pongo a resguardo a toda prisa, pereceré yo mismo y todos a quienes se me ha confiado.
} 
A la postre, la tensión entre utilidad y justicia exige siempre resolver de alguna manera. Conscientes de lo espinoso de la cuestión ${ }^{12}$ y de que no todo lo que resulta útil puede estimarse justo, arriesgamos que un criterio para adjetivar como justo un curso de acción en materia sanitaria quizá sea la observancia -en algún grado- de ciertos niveles de utilidad. Vale decir: no necesariamente la utilidad reclama a la justicia, pero sí ésta a aquélla; ergo, intuimos que entre las condiciones de la justicia, presumiblemente, figure la realización de la utilidad. No obstante, a todo evento, debe quedar en claro que no se trata de introducir variables que acaben por mercantilizar la salud sino de acusar recibo de la finitud de los recursos, so pena de embriagarse en un idealismo capaz de abonar la peregrina idea de que todo cuanto se desea resulta posible.

\section{Referencias}

ALEGRE, Marcelo; GARGARELLA, Roberto; ROSENKRANTZ, Carlos (Coords.). Homenaje a Carlos S. Nino. Buenos Aires: La Ley, 2008.

ARANGO, Rodolfo. Filosofía de la democracia. Bogotá: Siglo del Hombre, 2007.

ATRIA, Fernando. ¿Existen derechos sociales? Alicante: Biblioteca Virtual Miguel de Cervantes, 2005. (Edición digital a partir de Discusiones: Derechos Sociales, n. 4 (2004), p. 15-59).

BUCHANAN, Allen. The rigth to a decent minimun of health care. Philosophy \& Public Affairs, v. 13, n. 2, p. 55-78, 1984.

CLÉRICO, Laura, Proporcionalidad, prohibición de insuficiencia y la tesis de la alternatividad. Buenos Aires: La Ley, 2010.

DWORKIN, Ronald. Ética privada e igualitarismo político. Barcelona: Paidós, 1993.

Justice in the distribution of health care. McGill Law Journal, v. 38, n. 4, p. 883-898, 1993. Disponible en: <http://www.lawjournal.mcgill.ca/userfiles/other/4236093-Dworkin.pdf>.

\footnotetext{
${ }^{12}$ Sobre los debates en torno a la satisfacción de los derechos sociales y el paradigma de la escacez, conviene ver especialmente: ATRIA, Fernando. ¿Existen derechos sociales? Alicante: Biblioteca Virtual Miguel de Cervantes, 2005. (Edición digital a partir de Discusiones: Derechos Sociales, n. 4 (2004), p. 15-59); BUCHANAN, Allen. The rigth to a decent minimun of health care. Philosophy \& Public Affairs, v. 13, n. 2, p. 55-78, 1984; CLÉRICO, Laura, Proporcionalidad, prohibición de insuficiencia y la tesis de la alternatividad. Buenos Aires: La Ley, 2010; DWORKIN, Ronald. Ética privada e igualitarismo político. Barcelona: Paidós, 1993; Id. Justice in the distribution of health care. McGill Law Journal, v. 38, n. 4, p. 883-898, 1993. Disponible en: <http://www. lawjournal.mcgill.ca/userfiles/other/4236093-Dworkin.pdf>; ENGELHARDT, Hugo T. Los fundamentos de la bioética. Madrid: Paidos, 1995; GARGARELLA, Roberto. Las teorias de la Justicia después de Rawls: un breve manual de filosofía política. Barcelona: Paidos, 2004; GRSOMAN, Lucas. Escasez e igualdad: los derechos sociales en la Constitución. Buenos Aires: Editorial Libraria, 2008; NOZICK, Robert. Anarquía, Estado y utopía. México: Fondo de Cultura Económica, 1990; PUYOL-GONZÁLEZ, Ángel. Ética, derechos y racionamiento sanitário. Doxa: Cuadernos de Filosofía del Derecho, n. 22, p. 581-605, 1999. Disponible en: <http://www. cervantesvirtual.com/descargaPdf/etica-derechos-y-racionamiento-sanitario/>; RAWLS, John. Teoría de la justicia. México: Fondo de Cultura Económica, 1985; ZÚÑIGA FAJURI, Alejandra. Sistemas sanitarios y reforma AUGE en Chile. Acta Bioethica (OPS/OMS), v. 13, n. 2, 2007. Disponível em: <http://www.scielo.cl/ pdf/abioeth/v13n2/art12.pdf>. http://dx.doi.org/10.4067/S1726-569X2007000200012; entre otros.
} 
ENGELHARDT, Hugo T. Los fundamentos de la bioética. Madrid: Paidos, 1995.

GARGARELLA, Roberto. La justicia frente al gobierno. Barcelona: Ariel, 1996.

Las teorías de la Justicia después de Rawls: un breve manual de filosofía política. Barcelona: Paidos, 2004.

GRSOMAN, Lucas. Escasez e igualdad: los derechos sociales en la Constitución. Buenos Aires: Editorial Libraria, 2008.

NOZICK, Robert. Anarquía, Estado y utopía. México: Fondo de Cultura Económica, 1990.

PREGNO, Elian. Ideas generales para la construcción de una respuesta jurídica compleja, autónoma y transversal a los procesos salud-enfermedad-atención. Revista en Letra, año 1, n. extraordinario sobre Derecho de la Salud, p. 57-81, dic. 2014. Disponible en: <http://oaji. net/articles/2014/1341-1418596983.pdf>.

PUYOL-GONZÁLEZ, Ángel. Ética, derechos y racionamiento sanitário. Doxa: Cuadernos de Filosofía del Derecho, n. 22, p. 581-605, 1999. Disponible en: <http://www.cervantesvirtual. com/descargaPdf/etica-derechos-y-racionamiento-sanitario/>.

RAWLS, John. Teoría de la justicia. México: Fondo de Cultura Económica, 1985.

SANTIAGO JUÁREZ, Rodrigo. Participación y deliberación como correctores del sistema democrático. Estudios Fronterizos, v. 10, n. 20, p. 129-152, 2009.

ZÚÑIGA FAJURI, Alejandra. Sistemas sanitarios y reforma AUGE en Chile. Acta Bioethica (OPS/OMS), v. 13, n. 2, 2007. Disponible en: <http://www.scielo.cl/pdf/abioeth/v13n2/art12. pdf>. http://dx.doi.org/10.4067/S1726-569X2007000200012.

Elian Pregno - Doctor en el área de Filosofía del Derecho por la Facultad de Derecho de la Universidad de Buenos Aires. Profesor de la Facultad de Derecho de la Universidad de Buenos Aires. Buenos Aires, Argentina. E-mail: epregno@derecho.uba.ar. 